Check for updates

Cite this: RSC Adv., 2018, 8, 20593

\section{Facile synthesis of wavy carbon nanowires via activation-enabled reconstruction and their applications towards nanoparticles separation and catalysis $\dagger$}

\author{
Fengting Li, ${ }^{a}$ Chenxue Yao, ${ }^{b}$ Yiqun Zheng $\mathbb{D}^{* b}$ and Shifeng Hou $\mathbb{D D}^{\mathrm{b}}$
}

We report a facile synthesis of wavy carbon nanowires (WCNWs) derived from polyurethane via $\mathrm{KOH}$ activation. The success of this synthesis relies on a carefully designed activation procedure, which involved one pre-activation stage to form suitable precursor and one high-temperature activation stage to allow directional carbon reconstruction. In particular, $\mathrm{PU}$ was initially mixed with $\mathrm{KOH}$ and thermally treated sequentially at $400{ }^{\circ} \mathrm{C}$ and $800{ }^{\circ} \mathrm{C}$ for 1 hour, respectively. The resultant products exhibit high purity in the shape of wavy wire, together with a uniform diameter of $51 \pm 5.2 \mathrm{~nm}$ and the length in the range of 2-8 $\mu \mathrm{m}$. Systematic studies have been conducted to investigate the effect of reaction parameters in two activation stages on the morphology and structure of final products. It is worth noting that the as-prepared WCNWs could find promising use in the field of both nanoparticle separation and catalysis. For example, they exhibit outstanding separation abilities towards Au nanospheres with different sizes and enhanced catalytic performance when serving as the catalyst support for Pd towards ethanol oxidation reaction. Particularly, the peak current density of Pd/WCNWs catalysts can reach 2126

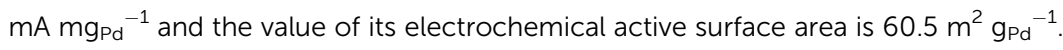

Received 27th March 2018 Accepted 30th May 2018

DOI: 10.1039/c8ra02639d

rsc.li/rsc-advances has become of great importance to explore feasible methods for synthesis of 1D carbons with tunable structure and properties.

Thanks to the research efforts contributed by many groups, it is now possible to fabricate $1 \mathrm{D}$ carbon nanomaterials via a number of techniques, including arc-discharging, ${ }^{15}$ thermal evaporation, ${ }^{8}$ laser ablation, ${ }^{16}$ electrospinning technique,${ }^{17}$ and chemical vapor deposition (CVD). ${ }^{18}$ For example, Lee and his colleagues first reported the synthesis of carbon nanowires (CNWs) by a thermal evaporation method in $1999 .^{8}$ They obtained an amorphous CNW with the diameter of around $40 \mathrm{~nm}$ by heating a pressed tablet of graphite powder mixed with $\mathrm{Ni}$ catalyst in a quartz tube mounted inside a high-temperature tube furnace at $1200{ }^{\circ} \mathrm{C}$. Azami and coworkers synthesized single-wall carbon nanohorn (SWCNH) with uniform and small diameter of about $50 \mathrm{~nm}$, another type of 1D nano-carbon materials, via $\mathrm{CO}_{2}$ laser ablation of graphite in Ne-gas atmosphere. ${ }^{16}$ As for synthesis of carbon nanofibers, electrospinning and following carbonization technique was always involved. Yang and coworkers fabricated dimensionally thin, mechanically tough, electrically conductive nanofibers with diameters in the range of $200-300 \mathrm{~nm}$ by electrospinning of a polymer solution (PAN) and subsequent thermal treatment. ${ }^{19}$ In addition, the chemical vapor deposition (CVD) method, including catalytic chemical vapor deposition (C-CVD) and catalytic plasma-enhanced chemical vapor deposition (C-PECVD), has been extensively investigated to prepare 1D carbon
${ }^{a}$ School of Chemistry and Chemical Engineering, Shandong University, Jinan, Shandong 250100, P. R. China

${ }^{b}$ National Engineering Research Center for Colloidal Materials, Shandong University, Jinan, Shandong 250100, P. R. China.E-mail:yiqunzheng@sdu.edu.cn; shifenghou@ sdu.edu.cn; Tel: +86-531-88363180; +86-531-88362815

$\dagger$ Electronic supplementary information (ESI) available. See DOI: $10.1039 / \mathrm{c} 8 \mathrm{ra02639d}$ 
nanomaterials. Dai and his co-workers synthesized kilogram scale of high quality single-walled carbon nanotubes (SWNTs) by the simple chemical vapor deposition of methane and they found that the success relied on the catalysts materials. ${ }^{20}$ Ostrikov and his colleagues fabricated metallic SWNTs and semiconducting carbon nanowires (CNWs) networks via slightly changing the process conditions in a simple CVD process using the same $\mathrm{Fe} / \mathrm{Al}_{2} \mathrm{O}_{3}$ catalyst. ${ }^{21}$ SWCNT was obtained when the catalysts were dewetted at $900{ }^{\circ} \mathrm{C}$ under a flow of $\mathrm{Ar}(200 \mathrm{sccm})$ for $5 \mathrm{~min}$. While the catalysts were pretreated at $1000{ }^{\circ} \mathrm{C}$ under a co-flow of $\mathrm{Ar}(200 \mathrm{sccm})$ and $\mathrm{H}_{2}(500 \mathrm{sccm})$ for $30 \mathrm{~min}$, CNWs were synthesized. All these successful demonstrations have contributed to development in the synthesis of $1 \mathrm{D}$ carbon nanomaterials with distinct shapes and tunable structures.

It is worth noting that in addition to those as-mentioned approaches, the formation of 1D carbon nanomaterials should also be possibly realized via carbon reconstruction under appropriate conditions. Similar to the interesting case of semiconductor nanowires formed via oriented attachment of quantum dots, ${ }^{22}$ it is not unreasonable to assume that carbon atoms and/or aggregates can also be attached or connected along one direction to promote the formation of carbon nanomaterials with 1D structure. However, this concept has been rarely put into practice and reported. Recently, the carbon reconstruction allowed by $\mathrm{KOH}$ activation has caused research attention. In particular, carbon reconstruction was triggered by broken carbon species and dangling bonds which were generated via $\mathrm{KOH}$ activation at high temperature. For example, carbon reconstruction has occurred during graphene oxide activation. A three dimensional (3D) porous carbon, named MEGO, could be obtained via a simple activation with $\mathrm{KOH}$ of microwave exfoliated two dimensional (2D) graphite oxide (MEGO) at $800{ }^{\circ} \mathrm{C}^{23}$ Later, Zhu and his colleagues found that the MEGO could remain quasi-2D morphology when $\mathrm{KOH}$ activation at relative low temperature of $450-500{ }^{\circ} \mathrm{C}$. While the activation temperature was above $500{ }^{\circ} \mathrm{C}$, a transition of quasi2D MEGO to 3D porous structure could be observed. ${ }^{24}$ In short, it would be helpful to take advantage of this process in the synthesis of $1 \mathrm{D}$ carbon nanomaterials.

Herein, we present a niche and facile method for the synthesis of $1 \mathrm{D}$ carbon nanomaterials with the shape of wavy nanowire via a carefully-designed $\mathrm{KOH}$ activation. In particular, polyurethane (PU) was mixed with $\mathrm{KOH}$ and pre-activated at $400{ }^{\circ} \mathrm{C}$, then followed by activation at $800{ }^{\circ} \mathrm{C}$. The morphology and structure of resultant products were characterized by scanning electron microscopy (SEM), transmission electron microscopy (TEM), high-resolution transmission electron microscopy (HRTEM), X-ray diffraction (XRD), Raman spectroscopy and X-ray photoelectron spectroscopy (XPS). Unlike 1D polymeric materials reported in previous studies, the atomic percentage of carbon in current product could reach up to 94.43\% (Table S1 $\dagger$ ). To this end, the current product could be considered as one niche type of 1D carbon nanomaterial with the wavy shape. Moreover, several reaction parameters involved in both activation stages have been systematically studied to investigate their effect on the wavy carbon nanowires formation (WCNWs). Furthermore, the as-prepared WCNWs were found useful in both nanoparticle separation and catalysis. In particular, WCNWs exhibits excellent separation abilities for $\mathrm{Au}$ nanoparticles with the size of 10 and $50 \mathrm{~nm}$. In addition, Pd/ WCNWs catalyst displays outstanding catalytic activities and stabilities for ethanol oxidation reaction (EOR). The mass peak current density of $\mathrm{Pd} / \mathrm{WCNWs}$ catalyst can reach $2126 \mathrm{~mA}$ $\mathrm{mg}_{\mathrm{Pd}}{ }^{-1}$ and stay at $459 \mathrm{~mA} \mathrm{mg}_{\mathrm{Pd}}{ }^{-1}$ after 1000 cycles.

\section{Experimental section}

\section{Materials}

Polyurethane (PU, 8670AU) was purchased from Bayer. Commercial Pd/C catalyst was obtained from Shanghai River Sen Electric Co., Ltd. Potassium hydroxide $(\mathrm{KOH},>85 \%)$, tetrachloroauric(III) acid hydrate $\left(\mathrm{AuCl}_{3} \mathrm{HCl} \cdot 4 \mathrm{H}_{2} \mathrm{O},>47.8 \%\right)$, sodium borohydride $\left(\mathrm{NaBH}_{4}, 98 \%\right)$, L-ascorbic acid (AA, $\geq 99.7 \%$ ), trisodium citrate dehydrate (TCD, $\mathrm{C}_{6} \mathrm{H}_{5} \mathrm{Na}_{3} \mathrm{O}_{7} \cdot 2 \mathrm{H}_{2} \mathrm{O}$, $\geq 99.0 \%)$, and isopropanol $\left(\mathrm{C}_{3} \mathrm{H}_{8} \mathrm{O}, \geq 99.7 \%\right)$ were all obtained from Sinopharm Chemical Reagent Co., Ltd. Hexadecyltrimethyl ammonium bromide (CTAB, 99\%), hexadecyltrimethyl ammonium chloride (CTAC, 97\%) and sodium tetrachloropalladate(II) $\left(\mathrm{Na}_{2} \mathrm{PdCl}_{4}, 98 \%\right)$ were all purchased from Shanghai Aladdin Bio-Chem Technology Co., Ltd. Poly(ethyleneimine) solution (PEI, average Mw 2000 by LS, $50 \mathrm{wt} \%$ in $\mathrm{H}_{2} \mathrm{O}$ ) was purchased from Sigma-Aldrich Co., Ltd. Alcohol $\left(\mathrm{CH}_{3} \mathrm{CH}_{2} \mathrm{OH}, 99.5 \%\right)$ and hydrochloric acid $(\mathrm{HCl}, 12 \mathrm{M})$ were both obtained Tianjin Fuyu Fine Chemical Co., Ltd. All the chemicals were used as received without further purification. The water used in all experiments was ultrapure water prepared by an ultrapure water system (Ulupure, Zhengzhou, China) with a resistivity of $18.25 \mathrm{M} \Omega \mathrm{cm}$ at room temperature. The quartz tube furnace (OTF-1200X) was purchased from Hefei Crystal Materials Technology Co., Ltd.

\section{Synthesis of wavy carbon nanowires (WCNWs)}

In a standard procedure for preparation of WCNWs, $0.15 \mathrm{~g}$ of PU was mixed with $0.6 \mathrm{~g}$ of $\mathrm{KOH}$ in a $30 \mathrm{~mL}$ agate mortar by dry milling for $10 \mathrm{~min}$ at room temperature to obtain a solid mixture of $\mathrm{PU} / \mathrm{KOH}$. The as-prepared solid mixture was heated in a tube furnace at the heating rate of $10{ }^{\circ} \mathrm{C} \mathrm{min}^{-1}$ under flowing argon at a flow rate of $100 \mathrm{~mL} \mathrm{~min}^{-1}$, pre-activated at $400{ }^{\circ} \mathrm{C}$ for $60 \mathrm{~min}$, and then activated at $800{ }^{\circ} \mathrm{C}$ for another $60 \mathrm{~min}$. After activation, the obtained black powder was neutralized with $\mathrm{HCl}(1 \mathrm{M})$ and washed with water until neutral $\mathrm{pH}$ was achieved. The resultant products were dried at $60^{\circ} \mathrm{C}$ in the open air for overnight.

\section{Fabrication of WCNWs filter membrane}

Filter membrane of the as-synthesized WCNWs was fabricated by a wet forming method using PEI as binder. In a typical experiment, $6 \mathrm{mg}$ of WCNWs was dispersed in $2 \mathrm{~mL}$ of water with ultra-sonication (ultrasonic power: $120 \mathrm{~W}$ ) for $60 \mathrm{~min}$ to form a $3 \mathrm{mg} \mathrm{mL}^{-1}$ suspension of WCNWs. Subsequently, $200 \mu \mathrm{L}$ of $0.5 \mathrm{wt} \%$ PEI was injected into the suspension in one shot using a pipette, and the resultant mixture was ultra-sonicated for another $120 \mathrm{~min}$. After that, the mixture was poured into 
a vacuum filter equipped with a $0.22 \mu \mathrm{m}$ porous PTFE membrane and filtered under low pressure $(-0.01 \mathrm{MPa})$ to produce a filter membrane followed by drying naturally.

\section{Preparation of $\mathbf{P d} / \mathbf{W C N W s}$ catalyst}

$15 \mathrm{mg}$ of the as-prepared WCNWs was dispersed in $30 \mathrm{~mL}$ of isopropanol with ultra-sonication (ultrasonic power: $120 \mathrm{~W}$ ) for $60 \mathrm{~min}$ to form a $0.5 \mathrm{mg} \mathrm{mL} \mathrm{m}^{-1}$ suspension of WCNWs. Next, $40 \mathrm{~mL}$ of aqueous TCD $(4.7 \mathrm{mM})$ solution was poured into the as-prepared suspension. The mixture solution was heated at $85{ }^{\circ} \mathrm{C}$ in an oil bath under magnetic stirring for $5 \mathrm{~min}$. Subsequently, $4.7 \mathrm{~mL}$ of aqueous solution containing $13.82 \mathrm{mg}$ of $\mathrm{Na}_{2} \mathrm{PdCl}_{4}$ was injected into the preheated solution in one shot using a pipette. The reaction solution was kept at $85{ }^{\circ} \mathrm{C}$ under magnetic stirring. After $6 \mathrm{~h}$, the products were collected by centrifugation, washed several times with water to remove excess TCD, and then dried at $60{ }^{\circ} \mathrm{C}$ in the open air for $6 \mathrm{~h}$.

\section{Synthesis of Au nanospheres with the diameter of $10 \mathrm{~nm}$ and $50 \mathrm{~nm}$}

The synthesis of Au nanospheres were conducted using seeded growth. The Au seeds were prepared according to a reported protocol. ${ }^{25}$ In a typical experiment, $5 \mathrm{~mL}$ of aqueous $\mathrm{HAuCl}_{4}(0.5$ $\mathrm{mM})$ solution and $5 \mathrm{~mL}$ of aqueous CTAB $(200 \mathrm{mM})$ solution were mixed in a $20 \mathrm{~mL}$ glass vial, then $0.6 \mathrm{~mL}$ of aqueous $\mathrm{NaBH}_{4}$ solution (10 $\mathrm{mM}$ ) was added rapidly using a pipette. A brown solution immediately emerged after the introduction of $\mathrm{NaBH}_{4}$ solution. The brown solution was remained at room temperature for $10 \mathrm{~min}$ to ensure complete decomposition of $\mathrm{NaBH}_{4}$ remaining in the mixed solution. For synthesis of $10 \mathrm{~nm} \mathrm{Au}$ nanospheres, $100 \mu \mathrm{L}$ of the $\mathrm{Au}$ seeds solution was added into a mixed $5.5 \mathrm{~mL}$ of aqueous solution containing $\mathrm{HAuCl}_{4}(0.18$ $\mathrm{mM})$, CTAC (72.72 $\mathrm{mM})$ and AA $(27.27 \mathrm{mM})$ in one shot using a pipette. The reaction was allowed to continue at room temperature for $10 \mathrm{~min}$. For synthesis of $50 \mathrm{~nm} \mathrm{Au}$ nanospheres, $2 \mathrm{~mL}$ of aqueous CTAC $(100 \mathrm{mM})$ solution, $150 \mu \mathrm{L}$ of aqueous AA (10 mM) solution and $10 \mu \mathrm{L}$ of $10 \mathrm{~nm}$ Au nanospheres aqueous solution were mixed in a $20 \mathrm{~mL}$ glass vital. Then $2 \mathrm{~mL}$ of aqueous $\mathrm{HAuCl}_{4}(0.5 \mathrm{mM})$ solution was dropped using a syringe pump at an injection rate of $2 \mathrm{~mL} \mathrm{~h}^{-1}$. The reaction was also allowed to proceed at room temperature for $10 \mathrm{~min}$ after the injection had been accomplished.

\section{Characterizations}

The morphology of as-prepared materials was observed using a field emission scanning electron microscope (FESEM, SU8010, HITACHI, Japan) operated at $5 \mathrm{kV}$ and transmission electron microscopy (TEM, JEM-1011, JEOL, Japan) at $120 \mathrm{kV}$. Highresolution TEM images were obtained using a field-emission microscope (HRTEM, JEM-2100F, JEOL, Japan) operated at $200 \mathrm{kV}$. Raman spectra were recorded via a high-resolution confocal-Raman system (LabRam HR800, HORIBA Jobin Yvon, Japan) with $633 \mathrm{~nm}$ lasers. X-ray diffraction (XRD) patterns were recorded by Bruker D8-Advance diffractometer (Bruker Ltd, Germany) with filtered $\mathrm{Cu}-\mathrm{K} \alpha$ radiation $(40 \mathrm{kV}, 40 \mathrm{~mA}$, $10^{\circ} \mathrm{min}^{-1}$ from 10 to $80^{\circ}$ ). X-ray photo electron spectroscopy
(XPS) spectra were recorded by a VG ESCALAB MKII X-ray photoelectron spectrometer with an $\mathrm{MgK}_{\alpha}$ excitation source $(1253.6 \mathrm{eV})$. The analysis of elements and their proportions in the products were performed with an elemental analyzer (vario EL cube, Elementar, Germany). The porous textures of the samples were analyzed by $\mathrm{N}_{2}$ adsorption/desorption at $77 \mathrm{~K}$ (ASAP 2020, Micromeritics, USA). The specific surface area was calculated using the BET method accorded to six points of relative pressure $\left(P / P_{0}\right)$ ranging from 0.05 to 0.08 . The total pore volume was measured from the amount of nitrogen adsorbed at a relative pressure $\left(P / P_{0}\right)$ of 0.99 . The pore size distribution was determined via density functional theory (DFT) method using nitrogen adsorption data. The tap density was calculated by the ratio of the mass to its tap volume, which was measured after the products were tapped 100 times in a vial. UV/vis extinction spectra were recorded on a U-4100 UV/VIS/NIR spectrometer (HITACHI, Japan). All the electrochemical experiments were carried out on a CHI-760E electrochemical workstation (Chenhua, Shanghai, China).

\section{Electrochemical measurement}

The catalytic performance and stability of the as-synthesized Pd/WCNWs catalyst for EOR under alkaline conditions were examined in a three-electrode system by cyclic voltammetry (CV) and chronoamperometry using a CHI-760E electrochemical workstation. In the test, a platinum foil, a saturated calomel electrode (SCE), and a glassy carbon electrode (GCE, diameter: $3.0 \mathrm{~mm}$ ) were used as the counter, reference, and working electrodes, respectively. For measurement, $4 \mathrm{mg}$ of as-prepared $\mathrm{Pd} /$ WCNWs catalyst was dispersed in a mixture solution of water $(2.0 \mathrm{~mL})$, isopropanol $(2.0 \mathrm{~mL})$ and Nafion solution $(10 \mu \mathrm{L}$, $5 \mathrm{wt} \%$ ) with ultra-sonication (ultrasonic power: $120 \mathrm{~W}$ ) for $30 \mathrm{~min}$ to form homogeneous suspension. $10 \mu \mathrm{L}$ of the asprepared homogeneous suspension was dropped on the surface of GCE and dried in the open air at $60^{\circ} \mathrm{C}$. As control, the catalytic performance of commercial $\mathrm{Pd} / \mathrm{C}$ catalyst on the GCE was also tested by similar process.

\section{Results and discussion}

\section{Morphology and structure}

As shown in Scheme 1, PU was first mixed with $\mathrm{KOH}$ by dry milling and thermally pre-activated at $400{ }^{\circ} \mathrm{C}$ and then activated at high temperature of $800{ }^{\circ} \mathrm{C}$ to form WCNWs. The weight yield of WCNWs was $20 \%$ versus the weight of raw PU. In addition, the tap density of WCNWs is $0.09 \mathrm{~g} \mathrm{~cm}^{-3}$. The morphology of WCNWs (see Experimental section for synthetic details) was characterized via typically scanning electron microscopy (SEM) and transmission electron microscopy (TEM). Fig. 1a and b, exhibit SEM images of WCNWs in different magnifications,

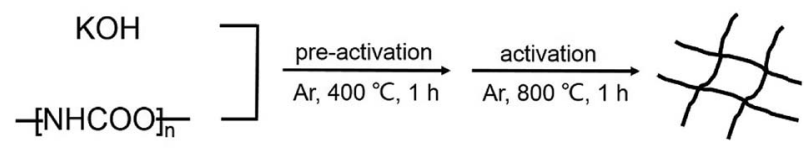

Scheme 1 Schematic illustration of the formation of WCNWs. 
from which we can see clearly that WCNWs were obtained in high purity, together with an average diameter of $51 \pm 5.2 \mathrm{~nm}$ and the length in the range of 2-8 $\mu \mathrm{m}$ (Fig. S1, ESI $\dagger$ ). Unlike carbon fibers which are straight and smooth, ${ }^{26}$ these WCNWs are curvy and rough, indicating their different internal structures and a great potential for applications in metal nanoparticles carrier. The curvy and rough structure can be observed clearly with TEM image (Fig. 1c). The inset in Fig. 1d shows the selected-area electron diffraction (SAED) pattern obtained from an individual WCNW, indicating that the WCNWs are mainly amorphous or full of defects, probably due to the $\mathrm{KOH}$ activation and/or relative low growth temperature.

XRD and Raman spectra were obtained to further investigate the structure and crystallinity of the WCNWs (Fig. 2). XRD pattern in Fig. 2a reveals two broad peak at about $2 \theta=23^{\circ}$ and $43^{\circ}$, which are ascribed to the (002) and (100) reflections typically observed for microcrystalline, semi-graphitic carbons. ${ }^{27}$ The high intensity in the low angle region probably results from $\mathrm{KOH}$ activation, demonstrating the amorphous structure of the WCNWs. Raman spectrum in Fig. $2 \mathrm{~b}$ further reveals the amorphous structure of WCNWs. The peaks appeared at 1320 and $1580 \mathrm{~cm}^{-1}$ can be attributed to the $\mathrm{D}$ (defects and disorder) and $\mathrm{G}$ (graphitic) bands of carbon materials, respectively. ${ }^{28}$ Generally, the $\mathrm{D}$ band corresponds to the breathing mode of $k$-point phonons of $A_{1 \mathrm{~g}}$ symmetry, while the G band corresponds to the $\mathrm{E}_{2 \mathrm{~g}}$ phonons of $\mathrm{sp}^{2}$ carbon atoms. ${ }^{29}$ Furthermore, the value of $\mathrm{D} /$ $\mathrm{G}$ intense ratio of WCNWs is 1.10 , indicating the structure of WCNWs is more amorphous, which is agreement with the diffuse diffraction ring in the inset of Fig. 1d. We can conclude that the as-obtained WCNWs have amorphous structure together with a wavy wire-like shape. Furthermore, $\mathrm{N}_{2}$ adsorption/desorption has been performed to investigate the specific surface area and pore size of the WCNWs. Indeed, the specific surface area of WCNWs is up to $845 \mathrm{~m}^{2} \mathrm{~g}^{-1}$. As shown in Fig. 2c, the isotherms is identified as type IV, illustrating that WCNWs is typical of micro- and mesoporous materials, which is confirmed by pore size distribution in Fig. $2 \mathrm{~d}^{30}$

Fig. 3a shows the XPS survey spectra of WCNWs, where two primary peaks centered at 285.8 and $534.4 \mathrm{eV}$ are observed, corresponding to $\mathrm{C} 1 \mathrm{~s}$ and $\mathrm{O} 1 \mathrm{~s}$, respectively. The spectra of $\mathrm{C} 1 \mathrm{~s}$ in Fig. $3 \mathrm{~b}$ can be fitted to three line shapes with binding energies at $284.5,285.2$ and $286.1 \mathrm{eV}$, corresponding to $\mathrm{C}-\mathrm{C}, \mathrm{C}-\mathrm{O}$ and $\mathrm{C}=\mathrm{O}$, respectively. It can be deduced that two functional groups exist on the surface of WCNWs besides the C-C peak, which is located at $284.5 \mathrm{eV} .^{31}$ The spectra of $\mathrm{O} 1 \mathrm{~s}$ in Fig. $3 \mathrm{c}$ exhibit peaks at $532.3(\mathrm{C}=\mathrm{O})$ and $533.8 \mathrm{eV}(\mathrm{C}-\mathrm{O})$, revealing the existence of carbonyl and other oxygen groups, which is consistent with the results shown in Fig. 3b. Taken together, the surface of as-prepared WCNWs contains numerous oxygencontaining functional groups.

In addition, the surface chemical composition of WCNWs was analyzed by X-ray photoelectron spectrometer. As shown in Table $\mathrm{S} 1, \dagger$ the atomic percentage of carbon and oxygen in WCNWs is $94.43 \%$ and $5.57 \%$, respectively. We can also enhance the carbon content in the current products by calcination under $\mathrm{Ar} / \mathrm{H}_{2}(95 / 5)$ flow at $1000{ }^{\circ} \mathrm{C}$ for $1 \mathrm{~h}$. In particular, the atomic percentage of carbon in the product reached $96.53 \%$ after calcination (Table S1 $\dagger$ ). Moreover, the elements and their proportions in the WCNWs were analyzed using an elemental analyzer. In addition to carbon and oxygen, WCNWs contained a small amount of hydrogen and nitrogen (Table S1†). It is worth noting that the calcination process caused unnoticeable change to the shape of the products and the wavy shape was still maintained (Fig. $\mathrm{S} 2 \dagger$ ).
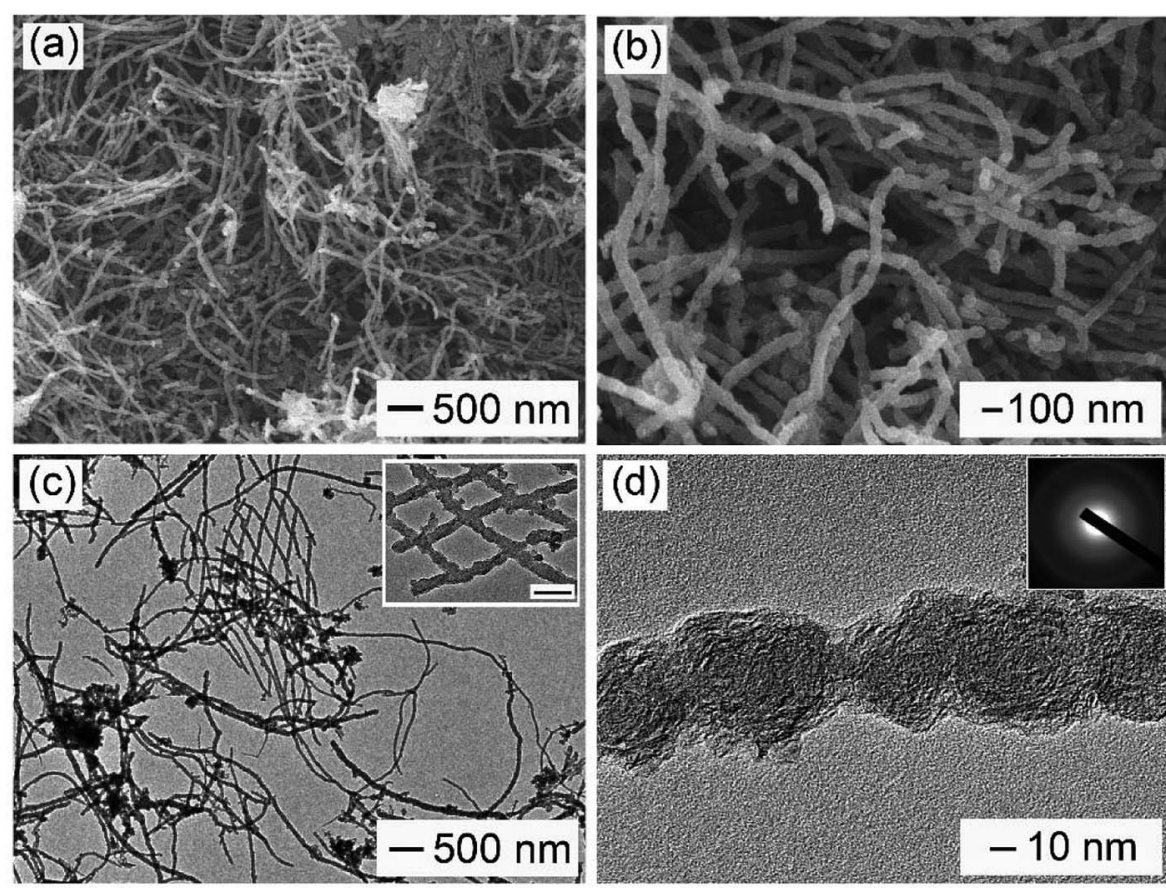

Fig. 1 (a) Low- and (b) high-magnification SEM images of WCNWs. (c) TEM and (d) high-resolution TEM images of WCNWs. The scale bar in the inset of part (c) is $100 \mathrm{~nm}$, and the inset of part (d) is the selected-area electron diffraction (SAED) pattern of the WCNWs. 
(a)

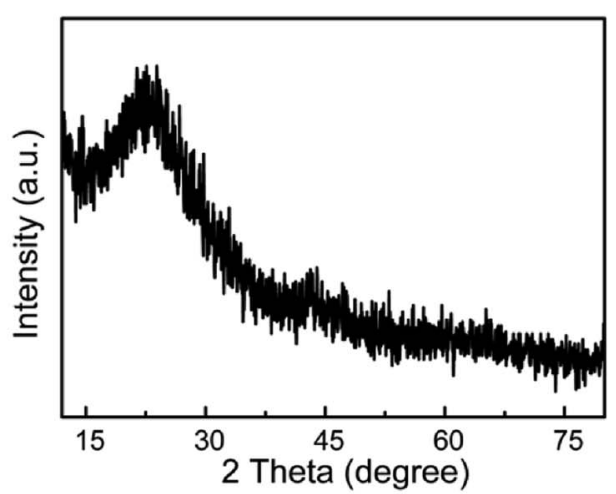

(c)

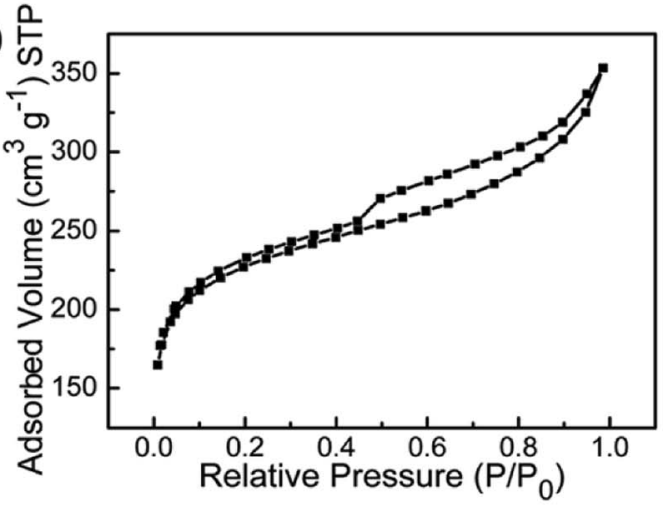

(b)
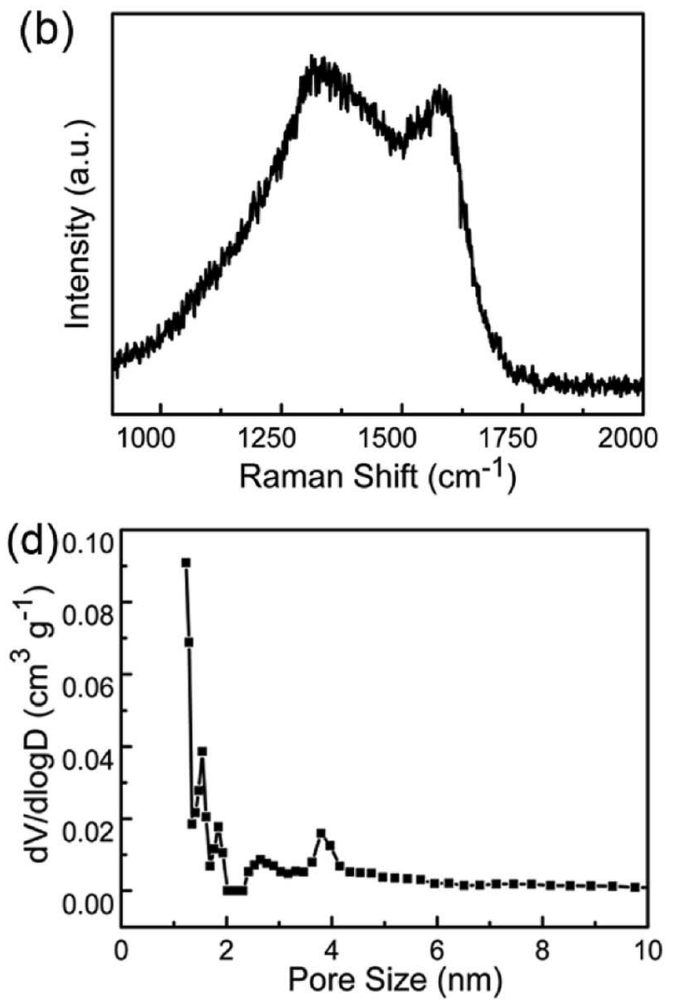

Fig. 2 (a) XRD pattern and (b) Raman spectrum of WCNWs. (c) $\mathrm{N}_{2}$ adsorption/desorption isotherm and (d) pore size distribution curve of WCNWs.

\section{Discussion on the formation mechanism}

Effect of the amounts of $\mathrm{KOH}$ : to investigate the mechanism involved in the formation of WCNWs, we conducted a set of control experiments. We first examined the effect of the amounts of $\mathrm{KOH}$, which had a direct correlation with the activation degree. When $\mathrm{KOH}$ was absent, only carbon monoliths was obtained (Fig. S3a $\dagger$ ), indicating the necessary presence of $\mathrm{KOH}$ in the current procedure. When the mass ratio of PU to $\mathrm{KOH}$ was set to $1: 1$ and $1: 3$, carbon fragments were obtained (Fig. S3b and $\mathrm{c} \dagger$ ). As more $\mathrm{KOH}$ was introduced (the mass ratio of $1: 5$, Fig. S3d $\dagger$ ), products with the uniformity in both shape and size were obtained, which was similar to the results exhibited in Fig. 1. However, when the mass ratio was increased to $1: 6$, the product yield was pretty low and no solid residue was left after the activation. These results demonstrated that the amount of $\mathrm{KOH}$ played an important role in synthesis of WCNWs. Consequently, the optimum mass ratio of $\mathrm{PU}: \mathrm{KOH}$ for synthesis of WCWNs was chosen at $1: 4$.

Effect of activation temperature: in order to elucidate the effect of activation temperature on the formation of WCNWs, products obtained at different activation temperatures were collected for SEM characterization. As shown in Fig. 4a, at the activation temperature of $400{ }^{\circ} \mathrm{C}$, only carbon monolithic, instead of WCNWs, was observed. As the activation temperature increases, e.g., to $600{ }^{\circ} \mathrm{C}$, carbon chunks with a fraction of WCNWs were obtained, as exhibited in Fig. $4 \mathrm{~b}$, indicating that a restructuring to $1 \mathrm{D}$ carbon began to occur at this reaction condition. As the activation temperature raised up to $900{ }^{\circ} \mathrm{C}$, many WCNWs were formed during the activation procedure
(Fig. 4c). It was noticeable that these WCNWs obtained at $900{ }^{\circ} \mathrm{C}$ were shorter in length than those of synthesized via a standard experiment at $800{ }^{\circ} \mathrm{C}$ (Fig. 1), probably due to the enhanced intensity of $\mathrm{KOH}$ activation increased at higher temperature. When the activation temperature further increases to $1000{ }^{\circ} \mathrm{C}$, no residue was collected after the reaction had been finished. Previously, it has been documented that 2D reduced graphene oxide could reconstruct to $3 \mathrm{D}$ porous carbons under $\mathrm{KOH}$ activation at $450{ }^{\circ} \mathrm{C} .{ }^{24}$ This carbon reconstruction process was also observed in our case when activation temperature reached $600{ }^{\circ} \mathrm{C}$.

Effect of pre-activation temperature: the current synthesis involved two stages of thermal treatment. In addition to the activation stage, we also investigated the effect of pre-activation temperature on the formation of WCNWs. Fig. 4d shows the typical SEM image of the resultant product obtained without a pre-activation procedure. We noted that only a few short and thin carbon nanowires are observed, illustrating a low yield of WCNWs under this reaction condition. It suggested the preactivation stage was beneficial for an enhanced yield of wireshaped product. As shown in Fig. 4e, when the pre-activation temperature was set to $300{ }^{\circ} \mathrm{C}$, some quasi-spherical particles occurred. In contrast, as the pre-activation temperature further increases to $500{ }^{\circ} \mathrm{C}$, only polyhedral carbons were observed (Fig. 4f). These results showed that the pre-activation temperature should be optimized at $400{ }^{\circ} \mathrm{C}$ for the best yield of WCNWs. To further elucidate the pre-activation temperature effect, we collected precursors obtained at different preactivation temperature for SEM and/or TEM characterization. As exhibited in Fig. S4a and b, $\uparrow$ PU was transformed into small 

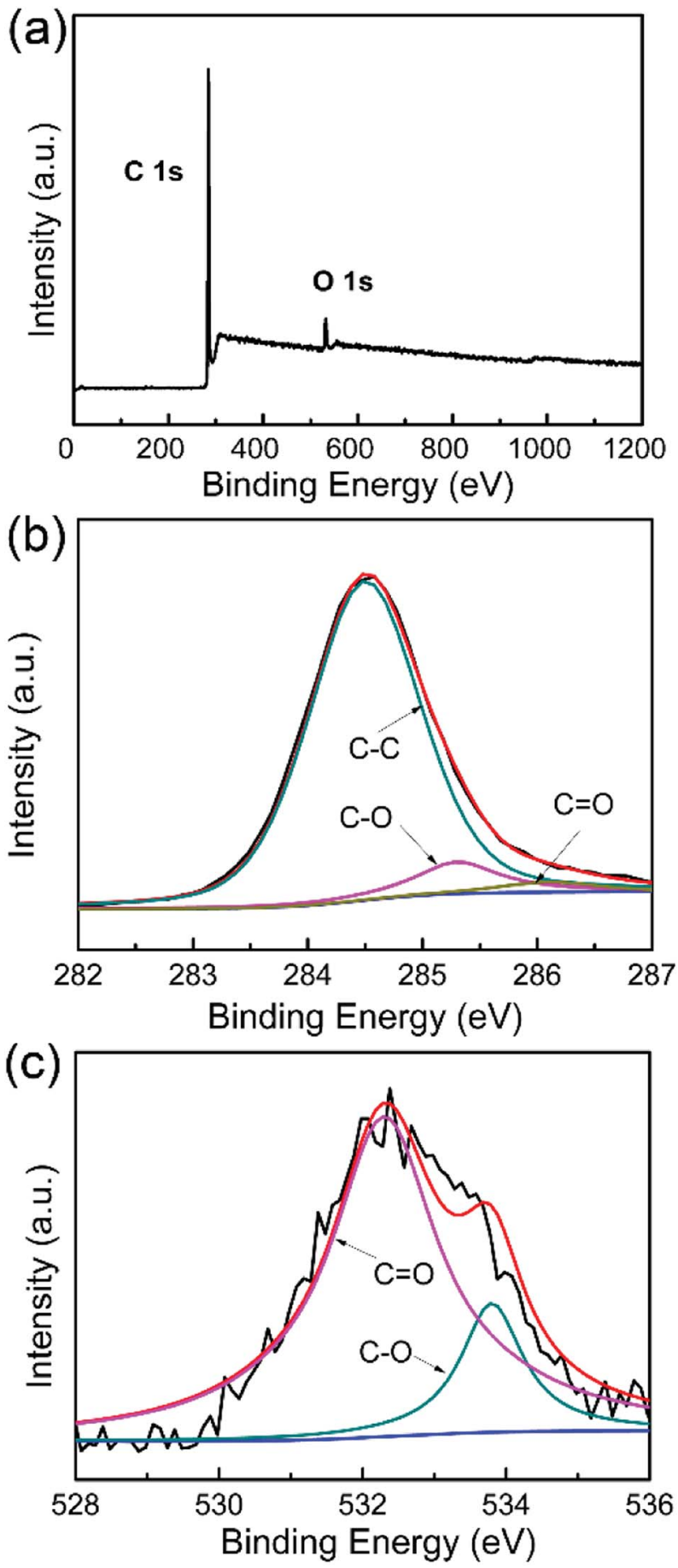

Fig. 3 (a) XPS survey spectra of WCNWs. (b and c) High resolution XPS spectra of (b) C 1s and (c) $O 1 \mathrm{~s}$.

particles via $\mathrm{KOH}$ activated at $400{ }^{\circ} \mathrm{C}$ for $1 \mathrm{~h}$, which could be rearranged to $1 \mathrm{D}$ carbon of WCNWs at high activation temperature of $800{ }^{\circ} \mathrm{C}$ (Fig. 1). Furthermore, $\mathrm{N}_{2}$ adsorption/ desorption has been performed to investigate the specific surface area and pore size of the precursor obtained via preactivation at $400{ }^{\circ} \mathrm{C}$. Compared with WCNWs, the precursor has larger specific surface area of $1616 \mathrm{~m}^{2} \mathrm{~g}^{-1}$ and higher tap density of $0.12 \mathrm{~cm}^{3} \mathrm{~g}^{-1}$, probably due to the presence of more micropores in the precursor (Fig. $2 \mathrm{c}$ and $\mathrm{d}$ and $\mathrm{S} 5 \dagger$ ). By contrast, the precursor obtained at $300{ }^{\circ} \mathrm{C}$ consisted of quasi-sphere particles and bulks (Fig. S4c $\dagger$ ), which could be restructured to large carbon particles and/or quasi-wires during the activation procedure (Fig. 4e). For the samples collected at $500{ }^{\circ} \mathrm{C}$, carbon mass with irregular shape was observed (Fig. S4d†), which could be reconstructed into polyhedral carbon via $\mathrm{KOH}$ assisted activation (Fig. 4f). Therefore, it is no unreasonable to assume that pre-activation temperature may affect the formation of WCNWs by varying the morphology and structure of its precursors.

Effect of activation time: to track the growth process, we terminated the reaction at $800{ }^{\circ} \mathrm{C}$ for different periods and collected the sample for SEM imaging. As shown in Fig. S6, $\uparrow$ at $t$ $=1 \mathrm{~min}$, the sample was composed of large chunks, small particles aggregations, and thin WCNWs of around $25 \mathrm{~nm}$. As reaction proceeded to $10 \mathrm{~min}$, large chunks disappeared and only small particles aggregations and thin WCNWs existed. After another $20 \mathrm{~min}$, the diameter of the WCNWs became about $45 \mathrm{~nm}$. At $t=40 \mathrm{~min}$, the product was dominated with WCNWs and the small particles aggregations disappeared. Based on these data, we believed that the precursor changed to large chunks and small particle aggregations in the initial stages, followed by the reconstruction of these particles along one direction to form 1D WCNWs.

In short, the growth mechanism is discussed as follows. $\mathrm{KOH}$ was firstly decomposed according to the reaction: $2 \mathrm{KOH}$ $\rightarrow \mathrm{K}_{2} \mathrm{O}+\mathrm{H}_{2} \mathrm{O}(\mathrm{g})$. Then carbon reacted with gaseous water to produce carbon monoxide and hydrogen $\left(\mathrm{H}_{2} \mathrm{O}+\mathrm{C} \rightarrow \mathrm{CO}+\right.$ $\left.\mathrm{H}_{2}\right) .{ }^{32,33}$ Similar to preparation of carbon nanotube/nanofiber via CVD, the CO formed in situ could mediate with $\mathrm{H}_{2}$ via hydrogenation and/or disproportionation to generate carbon atoms/clusters. ${ }^{34}$ These carbon species work as building blocks for the carbon nanoparticles and WCNWs observed in the initial stage of activation (Fig. S6†). It is worth noting that, in order to obtain WCNWs in high purity, the amount of $\mathrm{KOH}$ had to be more than 3 times of PU (Fig. S3†). It suggested that the concentration of $\mathrm{CO} / \mathrm{H}_{2}$ affected by amount of $\mathrm{KOH}$ should reach a sufficiently high level to favor the generation of carbon atoms/clusters and thus allow the carbon reconstruction to occur. In contrast, when too much $\mathrm{KOH}$ was added (i.e., $\mathrm{KOH} /$ $\mathrm{PU}=6: 1$ ), all the carbon precursor would be converted to gaseous product and no solid residue could be obtained. In a sense, the catalytic function of $\mathrm{KOH}$ could affect the reaction kinetics for this synthesis, which is crucial for the carbon reconstruction and thus the formation of WCNWs.

\section{Applications of WCNWs in nanoparticle separation and catalysis}

It is well accepted that $1 \mathrm{D}$ carbon nanomaterials are highly promising for application in catalysis and separation membranes. ${ }^{35,36}$ Herein, we chose two models to explore their applications: (i) the separation ability towards gold $(\mathrm{Au})$ nanoparticles when made into separation membrane; (ii) catalytic performance for EOR in alkaline medium when working as the catalyst support. 

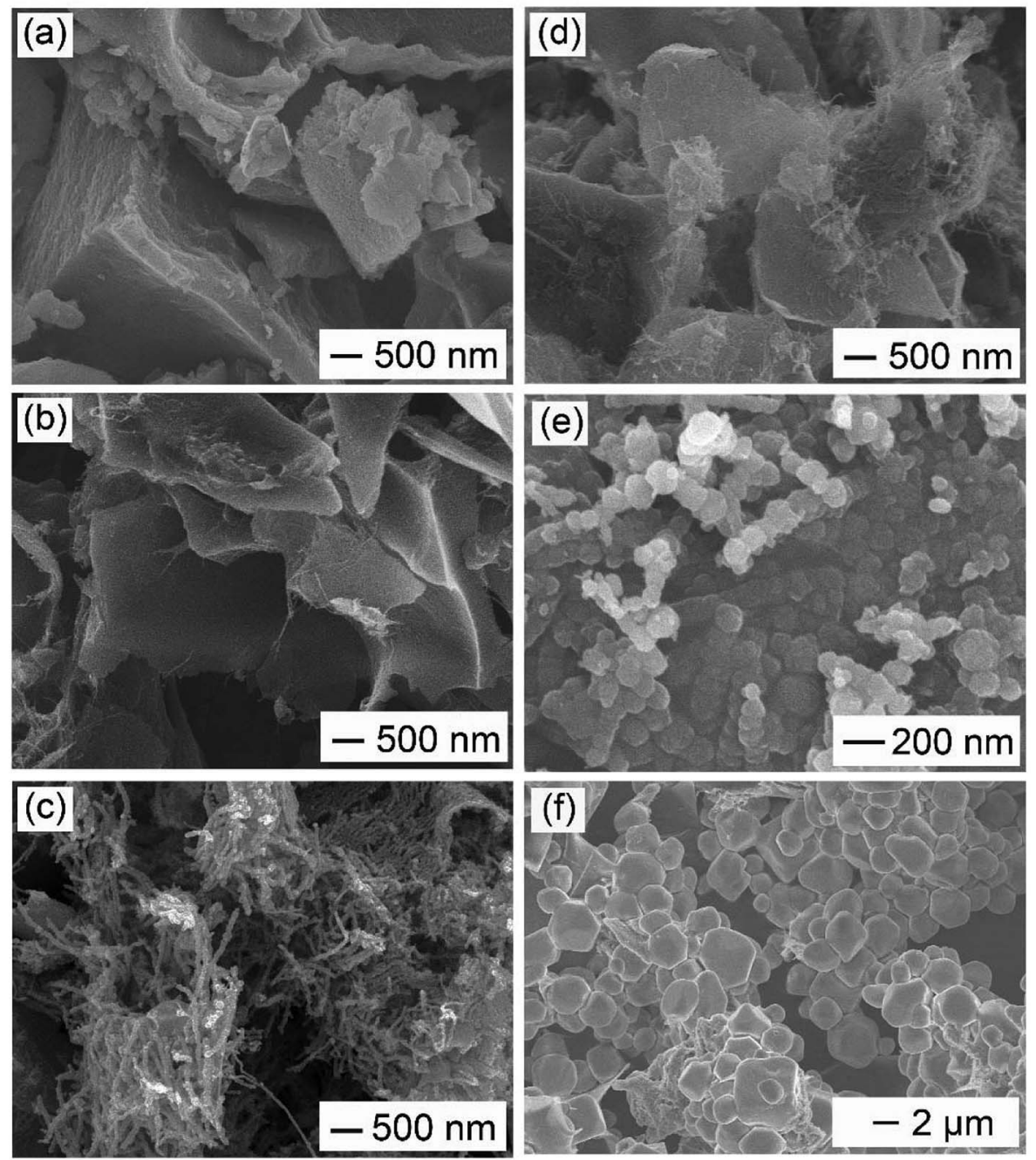

Fig. 4 Effect of activation and pre-activation temperature on the morphology and structure of the resultant products. (a-c) SEM images of products obtained via the standard procedure, except that the activation temperature was varied from $800{ }^{\circ} \mathrm{C}$ to (a) $400{ }^{\circ} \mathrm{C}$, (b) $600{ }^{\circ} \mathrm{C}$, and (c) $900{ }^{\circ} \mathrm{C}$, respectively; ( $\left.d-f\right)$ SEM images of products obtained via the standard procedure, except that (d) no pre-activation process was involved and (e and f) pre-activation temperature was varied from $400{ }^{\circ} \mathrm{C}$ to (e) $300{ }^{\circ} \mathrm{C}$ and (f) $500{ }^{\circ} \mathrm{C}$, respectively.

\section{Separation of Au nanospheres}

Optical and electronic properties of metal nanoparticles are strongly dependent on their shape, size, and uniformity. ${ }^{37}$ To obtain samples with high purity, separation is necessary. So far, the main methodologies for separation of nanoparticles include ultracentrifugation, field flow fraction, electrophoretic, magnetic and membrane separation methods..$^{35,38-42}$ We found that the as-prepared WCNWs could be fabricated into membrane to be used for separate $\mathrm{Au}$ nanospheres with different sizes of 10 and $50 \mathrm{~nm}$ from solution using the handmade setup (Fig. S7, $\dagger 5 \mathrm{a}$ ). As shown in Fig. 5a, $10 \mathrm{~nm} \mathrm{Au}$ spheres passed through the membrane, while $50 \mathrm{~nm}$ spheres were trapped on the membrane. The corresponding experimental results were exhibited in Fig. 5c. Almost all the $10 \mathrm{~nm} \mathrm{Au}$ nanospheres could freely pass through the membrane and about only $4.3 \%$ of them were remained inside the membrane or on the feed side, which was calculated from the adsorption intensities at $521 \mathrm{~nm}$ (Fig. 5d). In sharp contrast to the permeation of $10 \mathrm{~nm}$ Au spheres, all of the $50 \mathrm{~nm}$ Au spheres were been filtered out from solution. As for the mixed aqueous solution of 10 and $50 \mathrm{~nm}$ spheres, its color became slight red after filtering compared to the initial red solution (Fig. 5c), together with the weak intensity of the absorption peak after filtering (Fig. 5d). Besides, UV/vis extinction spectra for the mixture revealed a peak at near $527 \mathrm{~nm}$, while the peak shifted to $521 \mathrm{~nm}$ after filtration, explaining that the filtrate only contained $\mathrm{Au}$ spheres of $10 \mathrm{~nm}$. In addition, Fig. 5b shows the photographs of WCNWs membrane, from which we can see clearly that the membrane can be bent even without any cracking. Furthermore, the WCNWs membrane was characterized by SEM before (Fig. S8a †) and after filtration (Fig. S8b $\dagger$ ). As shown in Fig. S8b, $\uparrow$ Au nanospheres of $50 \mathrm{~nm}$ were captured on the membrane. The aggregation appeared on the membrane probably resulted from the removal surfactant of Au nanospheres and thus insufficient protection keep nanoparticles being attached to each other. In a word, these results illustrated the outstanding separation ability of WCNWs membrane in screening out metal nanoparticles with different sizes. 


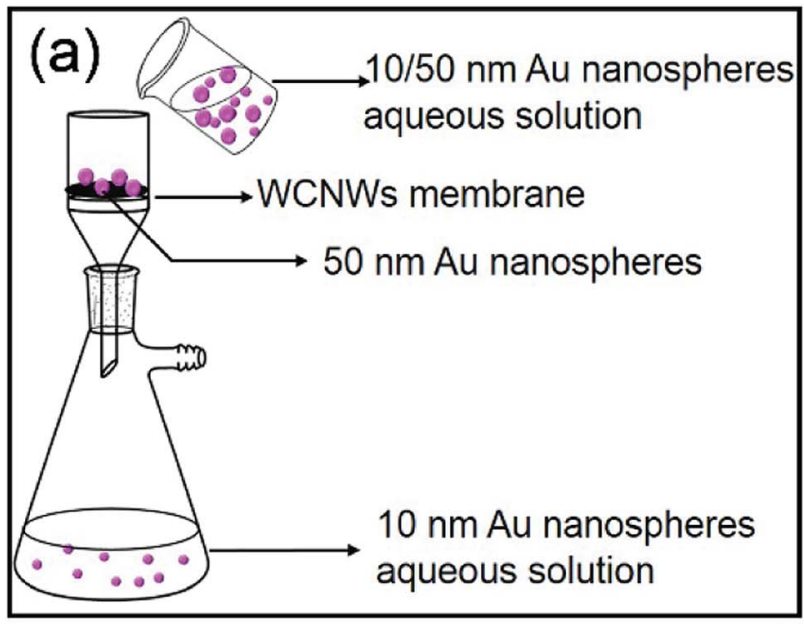

(c) Before

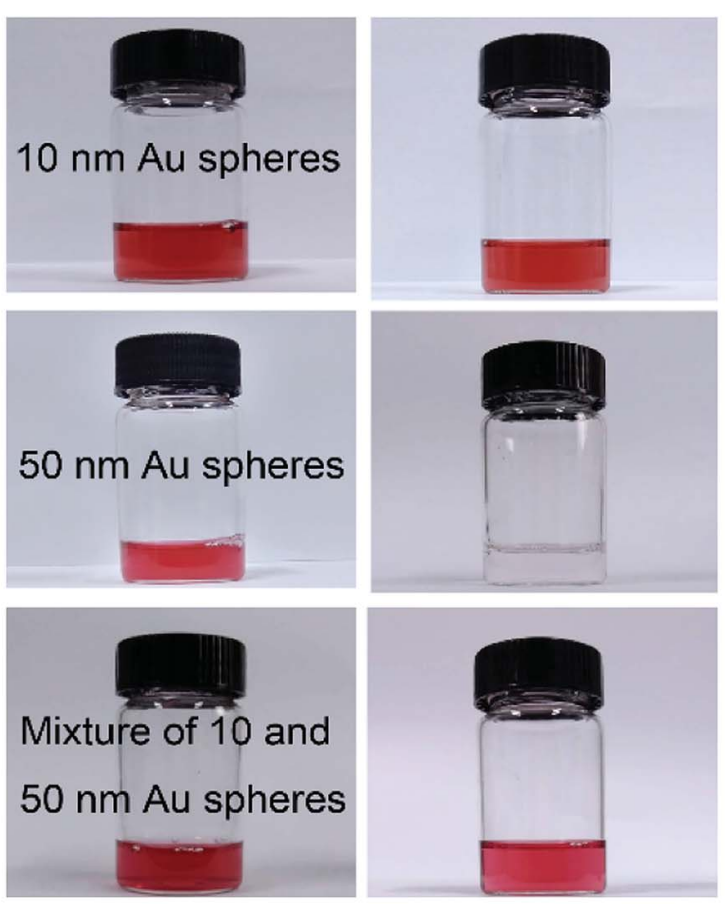

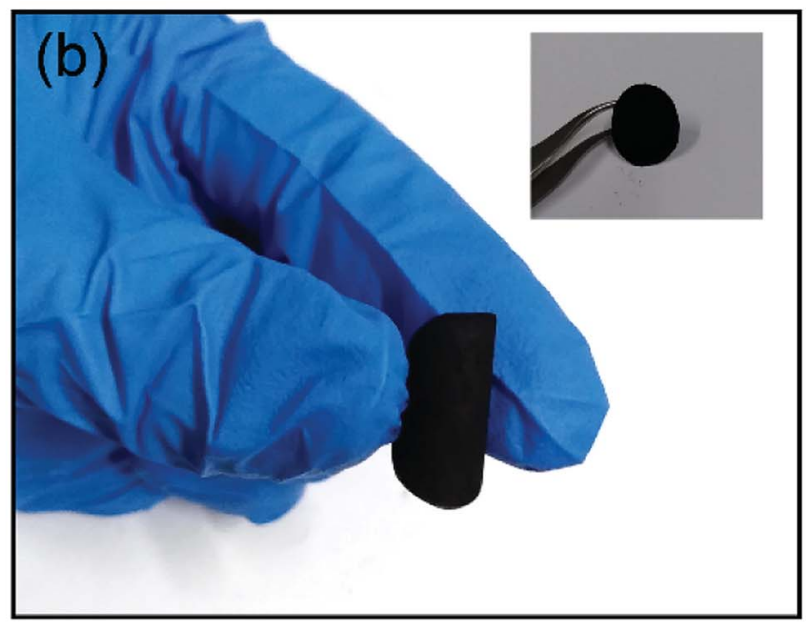

(d)
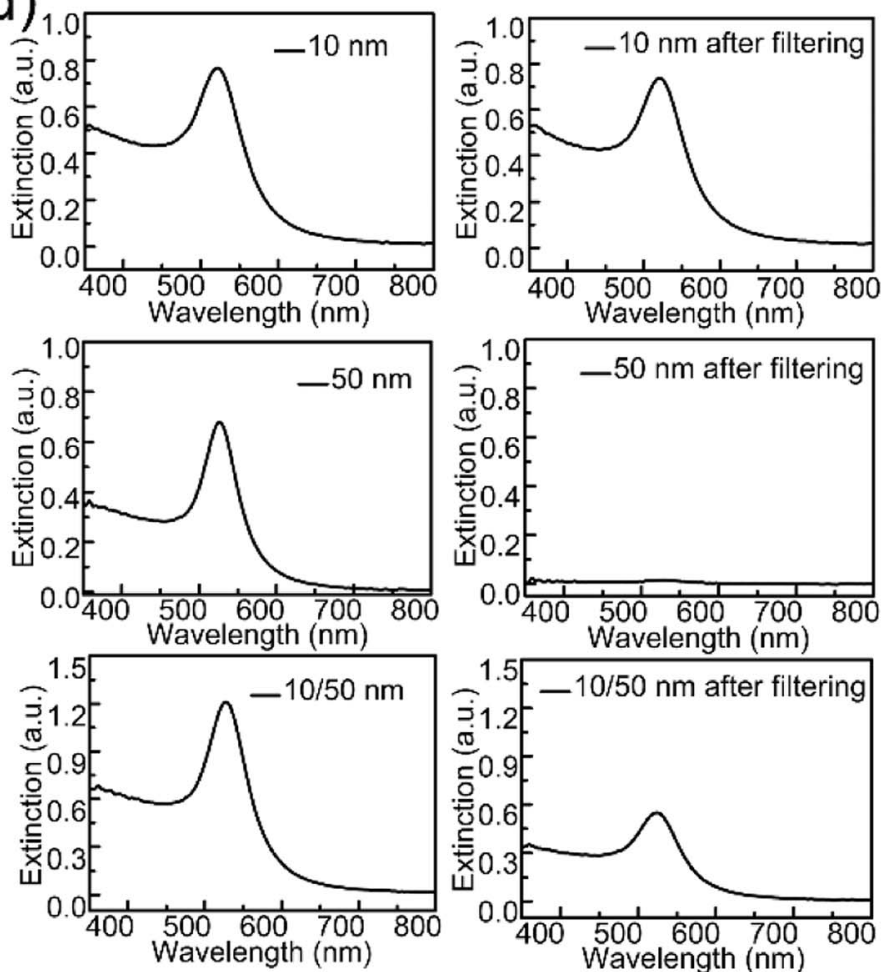

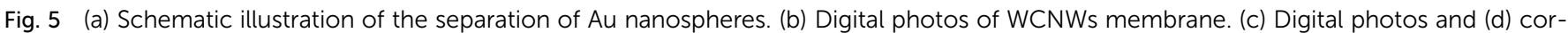
responding UV/vis extinction spectra of aqueous suspensions containing Au nanospheres with different sizes before and after filtering.

\section{Pd/WCNWs catalyst for ethanol oxidation reaction}

The as-prepared WCNWs was also found useful as catalyst support, which is probably due to their rough morphology and amorphous and/or full of defects structure, which could make it easier load Pd nanoparticles. The catalytic performance of $\mathrm{Pd} /$ WCNWs catalyst has been systematically investigated by $\mathrm{CV}$ experiments in a three-electrode system and the results were compared with that of commercial Pd/C catalyst. As shown in Fig. S9, $\uparrow$ Pd nanoparticles with uniform diameter were welldistributed on the surface of WCNWs. The electrochemically active surface area (ECSA) is a primary parameter for the evaluation of active sites of catalysts and can be calculated from the area of the reduction peak of palladium oxide in the CV curves in $1.0 \mathrm{M}$ of $\mathrm{KOH}^{43}$ Fig. 6a exhibits the typical CV curves of Pd/WCNWs and commercial $\mathrm{Pd} / \mathrm{C}$ catalysts in $1 \mathrm{M} \mathrm{KOH}$ solution at a scan rate of $50 \mathrm{mV} \mathrm{s}^{-1}$. The ECSA $\left(\mathrm{m}^{2} \mathrm{~g}_{\mathrm{Pd}}{ }^{-1}\right)$ is reckoned in reference to the equation $\mathrm{ECSA}=Q /\left(0.405 \times W_{\mathrm{Pd}}\right)$, where $Q$ is the coulombic charge by integrating peak area of the reduction of palladium oxide (mC) and $W_{\text {Pd }}$ means the palladium loading $\left(\mathrm{mg} \mathrm{cm}^{-2}\right)$ on the work electrode, respectively. In addition, 0.405 is the charge required for the reduction of palladium oxide monolayer $(\mathrm{mC}$ $\left.\mathrm{cm}_{\mathrm{Pd}}{ }^{-2}\right) .{ }^{44}$ Therefore, the value of ECSA of Pd/WCNWs catalyst is $60.5 \mathrm{~m}^{2} \mathrm{~g}_{\mathrm{Pd}}^{-1}$, which is nearly 2.67 times higher than that of commercial $\mathrm{Pd} / \mathrm{C}$ catalyst $\left(22.7 \mathrm{~m}^{2} \mathrm{~g}_{\mathrm{Pd}}{ }^{-1}\right)$, elucidating that WCNWs used as catalysts support could enhance the mass transfer compared to the activated carbon carrier. 

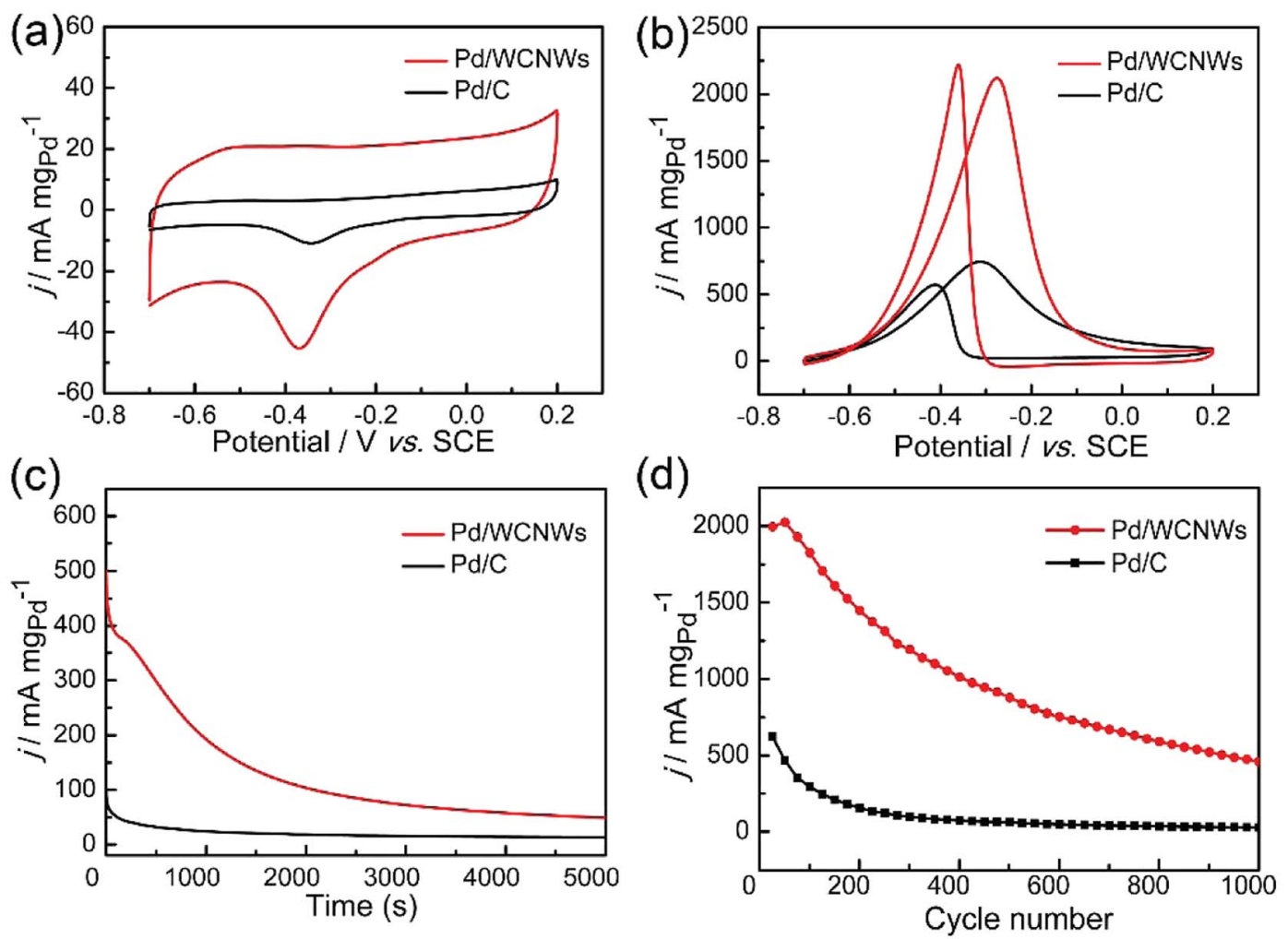

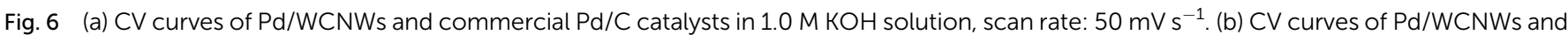
commercial $\mathrm{Pd} / \mathrm{C}$ catalysts in $1.0 \mathrm{M} \mathrm{KOH}+1.0 \mathrm{M} \mathrm{C}_{2} \mathrm{H}_{5} \mathrm{OH}$ solution, scan rate: $50 \mathrm{mV} \mathrm{s}^{-1}$. (c) Chronoamperometric curves of Pd/WCNWs and commercial $\mathrm{Pd} / \mathrm{C}$ catalysts in $1.0 \mathrm{M} \mathrm{KOH}+1.0 \mathrm{M} \mathrm{C}{ }_{2} \mathrm{H}_{5} \mathrm{OH}$ solution at $-0.4 \mathrm{~V}$. (d) The peak current density in the forward scan versus cycle number curves of $\mathrm{Pd} / \mathrm{WCNW}$ and commercial $\mathrm{Pd} / \mathrm{C}$ catalysts in $1.0 \mathrm{M} \mathrm{KOH}+1.0 \mathrm{M} \mathrm{C}_{2} \mathrm{H}_{5} \mathrm{OH}$ solution.

In addition, catalytic performance of $\mathrm{Pd} / \mathrm{WCNWs}$ and commercial $\mathrm{Pd} / \mathrm{C}$ catalysts towards EOR was measured in the solution of $1.0 \mathrm{M} \mathrm{KOH}$ and $1.0 \mathrm{M} \mathrm{C}_{2} \mathrm{H}_{5} \mathrm{OH}$ at $50 \mathrm{mV} \mathrm{s}^{-1}$. As shown in Fig. 6b, the characteristic ethanol oxidation peaks of both samples are observed in the forward and backward scans, respectively. Clearly, the peak current density (the value is normalized to the mass of $\mathrm{Pd}$ ) of Pd/WCNWs catalyst can reach $2126 \mathrm{~mA} \mathrm{mg}_{\text {pd }}{ }^{-1}$, which is about 3.25 times higher than that of commercial $\mathrm{Pd} / \mathrm{C}$ catalyst $\left(654.2 \mathrm{~mA} \mathrm{mg}_{\mathrm{Pd}}{ }^{-1}\right)$, indicating that the specific catalytic ability of the Pd/WCNWs catalyst is much higher than that of commercial Pd/C catalyst. Furthermore, the $\mathrm{Pd} / \mathrm{WCNW}$ catalyst shows much slower current decay over time than commercial Pd/C catalyst (Fig. 6c). In particular, after $1000 \mathrm{~s}$, the mass peak current density of Pd/WCNWs catalyst still remains of $192.7 \mathrm{~mA}$ $\mathrm{mg}_{\mathrm{Pd}}{ }^{-1}$, which is much higher than that of commercial Pd/C catalyst $\left(24.2 \mathrm{~mA} \mathrm{mg}_{\mathrm{Pd}}{ }^{-1}\right)$. Moreover, the long-term stability of the Pd/WCNWs and commercial Pd/C catalysts, that is, 1000 cycles of $\mathrm{CV}$ curves were performed in $1.0 \mathrm{M} \mathrm{KOH}+$ $1.0 \mathrm{M} \mathrm{C}_{2} \mathrm{H}_{5} \mathrm{OH}$ solution at a scan rate of $50 \mathrm{mV} \mathrm{s}^{-1}$, was shown in Fig. 6d. After 1000 cycles, the peak current density of Pd/ WCNWs catalyst maintains of $459 \mathrm{~mA} \mathrm{mg}_{\mathrm{Pd}}{ }^{-1}$, which is 21.17 times higher than that of commercial Pd/C catalyst (21.68 $\mathrm{mA} \mathrm{mg}_{\mathrm{Pd}^{-1}}$ ), indicating the excellent stability of $\mathrm{Pd} /$ WCNWs catalyst. As result, all the above discussions suggest that $\mathrm{Pd} / \mathrm{WCNWs}$ catalyst is more active and stable than commercial Pd/C catalyst for EOR, which may be mainly ascribed to the good electrochemical activity of Pd/WCNWs composites and the well-dispersed Pd nanoparticles.

\section{Conclusion}

In summary, we have developed a niche and facile method for synthesis of WCNWs derived from PU via KOH activationenabled carbon reconstruction. The structural transformation and coalescence were observed during the synthetic process. The amount of $\mathrm{KOH}$, pre-activation, and activation temperature have play important roles in the formation of WCNWs. Moreover, the as-prepared WCNWs exhibit outstanding separation ability towards Au nanospheres of 10 and $50 \mathrm{~nm}$. In addition, the as-synthesized WCNWs are also served as carrier for Pd catalyst towards EOR in alkaline medium, and they exhibits high catalytic activities and stabilities. In particular, the forward peak current density reaches $2126 \mathrm{~mA} \mathrm{mg}_{\mathrm{Pd}}{ }^{-1}$ and still keeps a high mass peak current density of $459 \mathrm{~mA} \mathrm{mg}{ }_{\mathrm{Pd}}{ }^{-1}$ after 1000 cycles. Due to their unique shape and structure, the as-synthesized WCNWs would hold widespread applications in the fields of wearable energy devices ${ }^{45,46}$ solar cells, ${ }^{47}$ and water purification. ${ }^{48,49}$

\section{Conflicts of interest}

The authors declare no competing financial interest. 


\section{Acknowledgements}

The authors appreciatively acknowledge financial support from the National Natural Science Foundation of China (Grant No. 21475076) and (Grant No. 21701100), and the International S\&T collaboration Program of China (No. 2015DFA50060).

\section{Notes and references}

1 H. W. Kroto, J. R. Heath, S. C. O'Brein, R. F. Curl and R. E. Smalley, Nature, 1985, 318, 162-163.

2 D. Ugarte, Nature, 1992, 359, 707-709.

3 X. Xu, R. Ray, Y. Gu, H. J. Ploehn, L. Gearheart, K. Raker, et al., J. Am. Chem. Soc., 2004, 126, 12736-12737.

4 L. A. Ponomarenko, F. Schedin, M. I. Katsnelson, R. Yang, E. W. Hill, K. S. Novoselov and A. K. Geim, Science, 2008, 320, 356-358.

5 O. A. Williams, Diamond Relat. Mater., 2011, 20, 621-640. 6 S. Iijima, Nature, 1991, 354, 56-58.

7 S. Iijima, M. Yudasaka, R. Yamada, S. Bandow, K. Suenaga, F. Kokai, et al., Chem. Phys. Lett., 1999, 309, 165-170.

8 Y. H. Tang, N. Wang, Y. F. Zhang, C. S. Lee, I. Bello and S. T. Lee, Appl. Phys. Lett., 1999, 75, 2921-2923.

9 K. S. Novoselov, A. K. Geim, S. V. Morozov, D. Jiang, Y. Zhang, S. V. Dubonos, I. V. Grigorieva and A. A. Firsov, Science, 2004, 306, 666-669.

10 A. B. Bourlinos, T. A. Steriotis, R. Zboril, V. Georgakilas and A. Stubos, J. Mater. Sci., 2009, 44, 1407-1411.

11 D. V. Kosynkin, A. L. Higginbotham, A. Sinitskii, J. R. Lomeda, A. Dimiev, B. K. Price and J. M. Tour, Nature, 2009, 458, 872-876.

12 Q. Sun, X.-Q. Zhang, F. Han, W.-C. Li and A.-H. Lu, J. Mater. Chem., 2012, 22, 17049.

13 Ihsanullah, A. Abbas, A. M. Al-Amer, T. Laoui, M. J. Al-Marri, M. S. Nasser, M. Khraisheh and M. A. Atieh, Sep. Purif. Technol., 2016, 157, 141-161.

14 O. Erol, I. Uyan, M. Hatip, C. Yilmaz, A. B. Tekinay and M. O. Guler, Nanomedicine, 2017, DOI: 10.1016/ j.nano.2017.1003.1021.

15 N. Arora and N. N. Sharma, Diamond Relat. Mater., 2014, 50, 135-150.

16 T. Azami, D. Kasuya, T. Yoshitake, Y. Kubo, M. Yudasaka, T. Ichihashi and S. Iijima, Carbon, 2007, 45, 1364-1369.

17 M. Inagaki, Y. Yang and F. Kang, Adv. Mater., 2012, 24, 25472566.

18 V. Georgakilas, J. A. Perman, J. Tucek and R. Zboril, Chem. Rev., 2015, 115, 4744-4822.

19 C. Kim, K. S. Yang, M. Kojima, K. Yoshida, Y. J. Kim, Y. A. Kim and M. Endo, Adv. Funct. Mater., 2006, 16, 23932397.

20 A. M. Cassell, J. A. Raymakers, J. Kong and H. Dai, J. Phys. Chem. B, 1999, 103, 6484-6492.

21 Z. J. Han, S. Yick, I. Levchenko, E. Tam, M. M. Yajadda, S. Kumar, P. J. Martin, S. Furmana and K. Ostrikov, Nanoscale, 2011, 3, 3214-3220.

22 N. Pradhan, H. Xu and X. Peng, Nano Lett., 2006, 6, 720-724.
23 Y. Zhu, S. Murali, M. D. Stoller, K. J. Ganesh, W. Cai, P. J. Ferreira, A. Pirkle, R. M. Wallace, K. A. Cychosz, M. Thommes, D. Su, E. A. Stach and R. S. Ruoff, Science, 2011, 332, 1537-1541.

$24 \mathrm{~S} . \mathrm{Wu}, \mathrm{G}$. Chen, N. Y. Kim, K. Ni, W. Zeng, Y. Zhao, Z. Tao, H. Ji, Z. Lee and Y. Zhu, Small, 2016, 12, 2376-2384.

25 Y. Zheng, X. Zhong, Z. Li and Y. Xia, Part. Part. Syst. Charact., 2014, 31, 266-273.

26 A. R. Postema, H. De Groot and A. J. Pennings, J. Mater. Sci., 1990, 25, 4216-4222.

27 A. D. Roberts, J.-S. M. Lee, S. Y. Wong, X. Li and H. Zhang, J. Mater. Chem. A, 2017, 5, 2811-2820.

28 Y. Zhang, S. Liu, X. Zheng, X. Wang, Y. Xu, H. Tang, F. Kang, Q.-H. Yang and J. Luo, Adv. Funct. Mater., 2017, 27, 1604687.

29 V. Wang, D. C. Alsmeyer and R. L. McCreery, Chem. Mater., 1990, 2, 557-563.

30 K. S. W. Sing, D. H. Everett, R. A. W. Haul, L. Moscou, R. A. Pierotti, J. Rouquerol and T. Siemieniewska, Pure Appl. Chem., 1985, 57, 603-619.

31 W. H. Lee, J. G. Lee and P. J. Reucroft, Appl. Surf. Sci., 2001, 171, 136-142.

32 J. Laine and A. Calafat, Carbon, 1991, 29, 949-953.

33 J. Laine, S. Simoni and R. Calles, Chem. Eng. Commun., 1991, 99, 15-23.

34 B. Zheng, C. Lu, G. Gu, A. Makarovski, G. Finkelstein and J. Liu, Nano Lett., 2002, 2, 895-898.

35 H. W. Liang, L. Wang, P. Y. Chen, H. T. Lin, L. F. Chen, D. He and S.-H. Yu, Adv. Mater., 2010, 22, 4691-4695.

36 Y. Liang, M. G. Schwab, L. Zhi, E. Mugnaioli, U. Kolb, X. Feng and K. Müllen, J. Am. Chem. Soc., 2010, 132, 15030-15037.

37 S. Eustis and M. A. El-Sayed, Chem. Soc. Rev., 2006, 35, 209-217.

38 G. Chen, Y. Wang, L. H. Tan, M. Yang, L. S. Tan, Y. Chen and

H. Chen, J. Am. Chem. Soc., 2009, 131, 4218-4219.

39 T. K. Mudalige, H. Qu, G. Sanchez-Pomales, P. N. Sisco and S. W. Linder, Anal. Chem., 2015, 87, 1764-1772.

40 N. Surugau and P. L. Urban, J. Sep. Sci., 2009, 32, 1889-1906.

41 E. R. Essinger-Hileman, E. J. Popczun and R. E. Schaak, Chem. Commun., 2013, 49, 5471-5473.

42 T. R. Gaborski, J. L. Snyder, C. C. Striemer, D. Z. Fang, M. Hoffman, P. M. Fauchet and J. L. McGrath, ACS Nano, 2010, 4, 6973-6981.

43 J. W. Hong, Y. Kim, D. H. Wi, S. Lee, S.-U. Lee, Y. W. Lee, S.-I. Choi and S. WooHan, Angew. Chem., Int. Ed., 2016, 2753-2758.

44 L. Chen, L. Lu, H. Zhu, Y. Chen, Y. Huang, Y. Li and L. Wang, Nat. Commun., 2017, 8, 14136.

45 S. Hong, J. Lee, K. Do, M. Lee, J. H. Kim, S. Lee and D.-H. Kim, Adv. Funct. Mater., 2017, 27, 1704353.

46 J. Zhong, Y. Zhang, Q. Zhong, Q. Hu, B. Hu, Z. L. Wang and J. Zhou, ACS Nano, 2014, 8, 6273-6280.

47 V. T. Tiong, N. D. Pham, T. Wang, T. Zhu, X. Zhao, Y. Zhang, Q. Shen, J. Bell, L. Hu, S. Dai and H. Wang, Adv. Funct. Mater., 2018, 1705545.

48 Y. Han, Z. Xu and C. Gao, Adv. Funct. Mater., 2013, 23, 36933700.

49 J. Ge, D. Zong, Q. Jin, J. Yu and B. Ding, Adv. Funct. Mater., 2018, 1705051. 